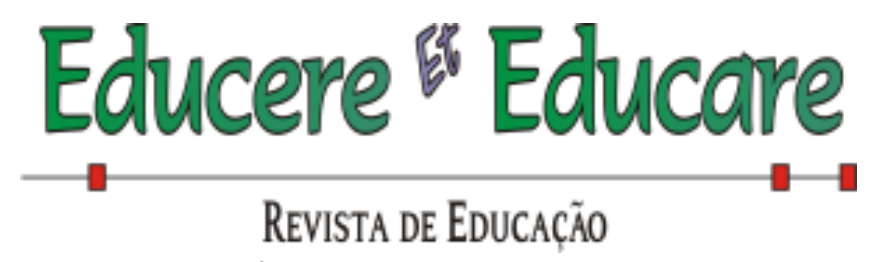

Programa de Pós-Graduação em Educação - Universidade Estadual do Oeste do Paraná

\title{
FINITUDE DA VIDA E EDUCAÇÃO: O CINEMA NA CONSTRUÇÃO DE VALORES LAICOS
}

\author{
Dr. Edilson Antedomenico \\ Dra. Marcia Reami Pechula
}

Universidade Estadual Paulista "Júlio de Mesquita Filho"

RESUMO: Neste trabalho apresentamos alguns resultados da pesquisa de Mestrado desenvolvida junto ao Departamento de Educação da Universidade Estadual Paulista "Júlio de Mesquista Filho", Campus de Rio Claro, entre 2012 e 2014, com o título: "O biodireito na interface entre ciência e ficção: um estudo do imaginário social a partir da análise do filme Mar Adentro". Para tanto, o presente artigo está estruturado em duas partes: na primeira, é feito um estudo para a compreensão dos aspectos éticos envolvidos com a terminalidade da vida humana, de modo a demonstrar a importância do processo educacional para a tomada de decisões mais livres, justas e conscientes. Na segunda parte, é feita uma leitura do filme Mar Adentro, cujas abordagens dilemáticas em torno da vida, da morte, da eutanásia, do suicídio assistido e do direito de morrer com dignidade permitem verificar se o filme pode contribuir para a ampliação dos conhecimentos necessários à reflexão bioética.

PALAVRAS-CHAVE: Eutanásia; Educação; Cinema.

\section{FINITUDE OF LIFE AND EDUCATION: THE CINEMA IN THE CONSTRUCTION OF LAIC VALUES}

\begin{abstract}
In this work we present some results of the Master's research developed by the Department of Education of the São Paulo State University "Júlio de Mesquista Filho", Campus of Rio Claro, between 2012 and 2014, with the title: "Biolaw in the interface between science and fiction: a study of the social imaginary from the analysis of the film Sea Inside". In order to do so, the present article is structured in two parts: in the first, a study is made to understand the ethical aspects
\end{abstract}

involved with the terminality of human life, in order to demonstrate the importance of the educational process for making freer decisions, fair and conscientious. In the second part, the film Sea Inside is read, whose dilemma approaches to life, death, euthanasia, assisted suicide and the right to die with dignity allow us to verify if the film can contribute to the expansion of the knowledge necessary for bioethical reflection.

KEYWORDS: Euthanasia; Education; Cinema. 


\title{
Educere "Educare \\ RevISTA DE EducAcão
}

Programa de Pós-Graduação em Educação - Universidade Estadual do Oeste do Paraná

\section{INTRODUÇÃO}

Ronald Dworkin (2003) defende que a humanidade caminha no sentido da separação entre as questões religiosas, deixadas a cargo das convicções morais, e as questões seculares, que devem ser decididas no âmbito ético-político. Entretanto, alguns assuntos ainda se encontram em conflito entre a laicidade e a religiosidade, devendo, por isso, ser refletidos por toda a sociedade, a fim de se atingir o ideário do Estado Democrático de Direito.

\begin{abstract}
A ordem jurídica de um Estado Democrático de Direito deve manter-se laica e secular, não podendo se converter na voz exclusiva da moral e, muito menos, da moral de qualquer religião. Há que se garantir a separação entre o sagrado e o profano, entre o dogma e a razão, entre a ética religiosa e a ética pagã. Em um Estado Democrático, todos devem ter a mesma liberdade para uma auto-compreensão ética. Mas, o proibicionismo, visto como um posicionamento ideológico de fundo moral, contrariando os princípios democráticos, tem a finalidade de promover ações politicas voltadas para a regulação e o controle de condutas, especialmente pela intervenção do sistema penal, e não permite espaço para as escolhas individuais, $o$ que $o$ torna eminentemente antidemocrático. (TJSP, 2009, p. 53-54).
\end{abstract}

É o que acontece, por exemplo, com a eutanásia e o suicídio assistido, ambos considerados crimes pelo nosso ordenamento jurídico.

No atual contexto brasileiro, parece não haver dúvidas de que quando um indivíduo não está satisfeito com sua própria vida, ele pode livremente dela dispor. Tanto é assim que se uma pessoa não logra êxito em seu suicídio, ela não será processada logo após. Diferentemente, se alguém induzir ou instigar outrem a suicidar-se ou prestar-lhe auxílio para que o faça, nasce para o Estado o jus puniendi, ou seja, o direito de punir quem praticou tal ato.

Mas e quando uma pessoa não pode cometer suicídio por conta de uma limitação física, como a tetraplegia, por exemplo? Corpo e espírito serão obrigados 


\section{Educere "Educare \\ ReVISTA DE EduCACÃo}

Programa de Pós-Graduação em Educação - Universidade Estadual do Oeste do Paraná

a permanecer aprisionados até que a morte os separe ou entra em cena a autonomia do sujeito para decidir sobre o fim de sua própria vida?

Nesse sentido, existem pessoas que lutam resolutamente pelo direito de morrer, como aconteceu, em junho de 2004, no Reino Unido, com o senhor Tony Nicklinson, quando ele sofreu um derrame que o deixou profundamente incapacitado para realizar as funções vitais básicas. Quase que completamente paralisado, ele ficou incapaz de falar e de realizar qualquer função física por conta própria, exceto movimentos limitados da cabeça, a denominada "síndrome do encarceramento" (CEDH, 2016).

Com o passar do tempo, Nicklinson decidiu gradualmente que não queria continuar a viver. Ele fez um testamento, em novembro de 2007, pedindo que todo o tratamento, exceto o de alivio da dor, acabasse - chegando a parar de tomar todo medicamento destinado a prolongar a sua vida. No entanto, por causa de suas deficiências, ele não conseguia se matar sem a assistência de outrem. Ele não queria causar dor e sofrimento à sua familia e queria uma saída mais humana e digna para sair do enclausuramento de seu próprio corpo, a morte. Por esse motivo, ele precisava da ajuda de um terceiro para colocar em prática a sua própria morte, o que foi negado pela Justiça. Por conta disso, Nicklinson recusou nutrição e tratamento médico, vindo a morrer de pneumonia em 22 de agosto de 2012.

O caso relatado diz respeito a um problema atual, a eutanásia e seus congêneres, a qual precisa ser discutida à luz de princípios éticos, livres de dogmatismos religiosos, que somente poderão ser construídos a partir de uma educação que discuta com seriedade o processo de morrer, sobretudo em um mundo cada vez mais tecnologizado.

Em verdade, é de se acreditar, que, a ausência, em grande parte, da morte em todas as formas, nos meios educacionais, deve-se a termos nos afastado da morte, em virtude de uma sociedade que cultiva a onipotência curativa, a manutenção da vida a qualquer preço e de qualquer forma, 


\section{Educere "Educare \\ ReVISTA de EduCAČ̃̃}

Programa de Pós-Graduação em Educação - Universidade Estadual do Oeste do Paraná

bem como as maneiras superficiais de manter a insuperável jovialidade e cultura do corpo. Desta forma, nos transformamos em uma sociedade que apenas fecha os olhos e silencia diante da morte, do Suicídio e da Eutanásia, as quais existem de forma marginalizada, de forma negligenciada, de forma renegada às margens das discussões acadêmicas e sociais. (MORAES; OLIVEIRA, 2010, p. 5).

O estudo aqui proposto, portanto, voltou-se, primeiramente, à compreensão dos aspectos éticos envolvidos com a terminalidade da vida humana, de modo a demonstrar a importância do processo educacional para a tomada de decisões mais livres, justas e conscientes.

$\mathrm{Na}$ segunda parte, será feita uma leitura do filme Mar Adentro, com o intuito de verificar se o filme pode contribuir para a ampliação dos conhecimentos necessários à reflexão bioética.

\section{Direito de morrer}

Lutar por uma condição de vida melhor parece fazer parte da natureza humana. A perplexidade ocorre quando essa luta deixa de ser em benefício da vida e passa a ser em prol da morte.

A legitimidade ou não dessa escolha envolve um universo de questões religiosas, morais e jurídicas. Existe um direito à morte, no tempo certo, a juizo do indivíduo? A ideia de dignidade humana, que acompanha a pessoa ao longo de toda sua vida, também poder ser determinante na hora de sua morte? Assim como há direito a uma vida digna, existiria direito a uma morte digna? Essas questões têm desafiado a Ética e o Direito pelos séculos afora. (BARROSO; MARTEL, 2012, p. 21-22).

Na Corte Europeia de Direitos Humanos, conforme relatório de pesquisa publicado em 2016, os casos levados a juízo envolvendo a luta pelo direito de morrer têm sido cada vez mais frequentes, o que a principio parece conter uma contradição, já que no imaginário sobre vida e morte, a luta e a ação dos sujeitos 


\section{Educere "Educare \\ RevISTA de EduCACÃo}

Programa de Pós-Graduação em Educação - Universidade Estadual do Oeste do Paraná

são entendidas como um componente da vida, e a morte como resignação ou derrota.

Assim, podemos citar o caso "Pretty v. the United Kingdom", julgado pela Corte em 29 de abril de 2002, no qual a demandante, portadora de uma doença neuromotora grave, incurável e degenerativa - que a impedia de cometer suicídio, pleiteava na Justiça que seu marido pudesse ajudá-la nessa missão, com a garantia de que ele não fosse processado em seguida.

Bem como o caso "Haas v. Switzerland", julgado em 20 de janeiro de 2011, no qual o reclamante, sofredor de um sério transtorno afetivo bipolar há cerca de vinte anos, argumentava que, por conta disso, não podia mais viver dignamente. Depois de ter tentado o suicídio em duas ocasiões, ele recorreu à Justiça para conseguir obter o pentobarbital sódico, cuja administração lhe permitiria terminar com sua vida de maneira segura e digna. Como essa substância só estava disponivel mediante receita médica, ele abordou vários psiquiatras para obtê-la, mas não obteve êxito. O demandante argumentava que o Estado suíço tinha uma "obrigação positiva" de criar as condições necessárias para que o seu suicídio ocorresse sem o risco de fracasso e sem dor, fornecendo-lhe a droga letal mesmo com a ausência da receita médica, como forma de garantir o direito ao respeito da vida privada.

E também o caso "Koch v. Germany", julgado em 19 de julho de 2012, no qual o marido da demandante, por conta de uma tetraplegia que a acometeu em 2002, solicitou ao Instituto Federal para Medicamentos e Dispositivos Médicos da Alemanha autorização para obter uma dose letal do pentobarbital de sódio para que ele ajudasse no suicídio de sua esposa em sua própria casa. Depois que a autorização foi recusada, em 12 de fevereiro de 2005, ela cometeu suicídio na Suíça, assistida pela organização Dignitas. O recorrente alegava que a recusa em conceder autorização à sua falecida esposa para adquirir uma dose letal da droga que permitiria acabar com a sua vida acabou violando tanto o direito dela como o seu próprio direito à intimidade e à vida privada e familiar. 


\section{Educere Educare \\ RevISTA De EduCAC̄̃o}

Programa de Pós-Graduação em Educação - Universidade Estadual do Oeste do Paraná

E, mais recentemente, podemos citar o caso do cientista australiano David Goodall, com então 104 anos de idade, que teve que se deslocar até a Suíça para receber, em 10/05/2018, assistência para o seu suicídio, o qual afirmava lucidamente que "os idosos deveriam ter o direito de decidir isto por si mesmos". Goodall não sofria de nenhuma doença, mas estava perdendo a visão e a audição, motivo pelo qual ele se alegrava de poder ver-se "aliviado" de tudo isso (ESTADÃO, 2018).

O cinema também tem debatido a questão da eutanásia, como exemplificam os filmes Menina de Ouro e Mar Adentro. Este último relata a história verídica de Ramón Sampedro (1943-1998), um jovem espanhol que ficou tetraplégico ao mergulhar no mar da costa da Galícia. Após o acidente, Ramón viveu praticamente 29 anos lutando convictamente na Justiça pelo direito de morrer.

Esses filmes e fatos ajudaram a ampliar a reflexão sobre questões éticas ligadas ao processo de morrer, em tempos de cuidados sempre mais tecnologizados. Além disso, criaram a oportunidade no contexto acadêmico científico, de promover muitas discussões éticas sobre a questão da morte e do morrer, da eutanásia, do direito de morrer com dignidade, questões jurídicas, religiosas e sociais envolvidas, corroborando, nesse sentido, para muitos esclarecimentos. (PESSINI, 2008, p. 52).

Portanto, é preciso refletir até que ponto e em que medida um indivíduo tem autonomia, bem como o direito, para decidir sobre o fim de sua própria vida.

\section{Bioética do fim da vida}

Dentre as grandes questões relacionadas ao término da vida humana, Kovács (2003, p. 116) destaca as seguintes: 


\section{Educere "Educare \\ RevisTa de EduCAČ̃̃}

Programa de Pós-Graduação em Educação - Universidade Estadual do Oeste do Paraná

1) Tem a pessoa o direito de decidir sobre a sua própria morte, buscando dignidade?

2) Pode-se planejar a morte?

3) Os profissionais da saúde, que têm o dever de cuidar das necessidades dos pacientes, podem atender a um pedido para morrer?

4) Podem ser interrompidos tratamentos que têm como objetivo apenas o prolongamento da vida, sem garantia da qualidade da mesma?

Diante de tal problemática, a bioética e o direito vêm sendo chamados a discutir o processo da morte, sobretudo diante das consequências que os avanços técnico-científicos podem causar nesse processo, pois hoje é possivel o prolongamento artificial da vida, o que leva a situações inusitadas em que corpo e espírito parecem já não estar mais unificados, tal como o leito de um rio que ali permanece inerte sem a correnteza de suas águas.

A ciência, portanto, vem intervindo, cada vez mais, no processo da morte. Isso é bom ou ruim? Todos terão acesso, se assim o quiserem, a essa tecnologia? E quem não quiser, como o fez o Papa João Paulo II, quando da irreversibilidade de seu quadro clínico, poderá reivindicar o direito de viver seus instantes finais de forma natural? E se a pessoa não tiver condições de decidir, a família poderá tomar a decisão? Estará nas mãos do Estado o poder de fazer viver e deixar morrer, como bem adverte Foucault (2005)?

Assim, Diniz (2013) destaca que tais avanços tecnológicos, frente à complexidade do tema morrer com dignidade, suscitam diversas questões éticojurídicas, a saber:

O sensacionalismo da mídia, alardeando casos isolados com fortes apelos sentimentais, não estaria tornando banal o direito à morte digna? Teria o paciente direito à autonomia da vontade, ou seja, a optar sobre fatos alusivos à sua própria pessoa, dando seu consenso esclarecido sobre o tratamento a ser seguido ou sobre a remoção de aparelho de sustentação de sua vida? Ao lado do direito de viver não haveria o de morrer com dignidade? Até que ponto e em que medida se poderia prolongar o processo do morrer, não mais havendo qualquer possibilidade de reverter o processo do morrer, não mais havendo qualquer possibilidade de reverter o quadro 


\title{
Educere Educare \\ RevISTA DE Educacão
}

Programa de Pós-Graduação em Educação - Universidade Estadual do Oeste do Paraná

\begin{abstract}
clínico? A quem interessaria manter a pessoa "morta-viva"? Por que se deve preservar a vida de um paciente terminal além dos limites de sua natureza? O prolongamento artificial da vida poderia ser, normalmente, considerado admissivel no contexto atual da civilização? Como conciliar a primazia dos direitos do paciente à assistência e à dignidade perante a morte, com o sofrimento de longa duração? "Morrer com dignidade" é consequência de viver dignamente ou uma sobrevivência sofrida? Se não há condições de vida digna, como assegurar uma morte digna? Poder-se-ia falar em desumanidade do homem para com o próprio homem? O direito ao respeito à dignidade humana não requereria a ausência de qualquer tratamento desumano, violento ou vexatório? Não seria um contrassenso o fato de uma mesma sociedade negar ao homem meios para viver e ofertar a ele tecnologia para "bem morrer"? Deveria o direito curvar- se às novas conquistar da medicina? Como tornar legal a escolha entre a vida e a morte? (DINIZ, 2011, p. 428).
\end{abstract}

Portanto, antes de mergulharmos nas profundezas de Mar Adentro, é de fundamental importância o apontamento de algumas distinções entre termos muito próximos, que geralmente são utilizados indiscriminadamente como sinônimos, sem maiores reflexões.

\section{Eutanásia e seus congêneres}

De acordo com Siqueira-Batista e Schramm (2005, p. 113), as modalidades mais úteis para a classificação da eutanásia baseiam-se no "ato em si" e no "consentimento do enfermo".

A distinção quanto ao ato seria: (a) Eutanásia ativa - ato deliberado de provocar a morte sem sofrimento do paciente, por fins humanitários (por exemplo, utilizando uma injeção letal); (b) Eutanásia passiva - quando a morte ocorre por omissão proposital sem se iniciar uma ação médica que garantiria a perpetuação da sobrevida (por exemplo, quando se deixa de ministrar um medicamento essencial à manutenção da vida do paciente); (c) Eutanásia de duplo efeito - nos casos em que a morte é acelerada como consequência de ações médicas não visando ao êxito letal, mas sim, ao alívio do sofrimento de um 


\section{Educere "Educare \\ ReVISTA DE EduCAC̄̃o}

Programa de Pós-Graduação em Educação - Universidade Estadual do Oeste do Paraná

paciente (por exemplo, emprego de morfina para controle da dor, gerando, secundariamente, depressão respiratória e óbito).

Já a distinção quanto ao consentimento do enfermo seria: (a) Eutanásia voluntária - em resposta à vontade expressa do doente - o que seria um sinônimo do suicídio assistido; (b) Eutanásia involuntária - quando o ato é realizado contra a vontade do enfermo, o que, em linhas gerais, pode ser igualado ao homicídio; (c) Eutanásia não voluntária - quando a vida é abreviada sem que se conheça a vontade do paciente.

Existem ainda outros termos que são utilizados para designar o fim da vida humana, tais como o suicídio assistido, a distanásia, a ortotanásia e a mistanásia, merecendo aqui uma descrição pormenorizada.

O suicídio assistido ocorre quando uma pessoa solicita o auxilio de outra para alcançar o óbito, caso não seja capaz de tornar fato sua disposição de morrer. Neste caso, o enfermo está, em princípio, sempre consciente manifestando sua opção pela morte -, enquanto na eutanásia nem sempre o doente encontra-se cônscio - por exemplo, na situação em que um paciente terminal e em coma está sendo mantido vivo por um ventilador mecânico, o qual é desligado, ocasionando a morte.

Contraposta à eutanásia e ao suicídio assistido tem-se a distanásia também identificada pars pro toto com a denominada obstinaçao terapêutica - a qual tem como interfaces tanto a aplicação de novas tecnologias à medicina - capazes de manter as funções biológicas, com amplas possibilidades para salvar grande número de vidas - quanto o arcaico desejo humano de superar a morte. [...] Atualmente é compreendida como manutenção da vida por meio de tratamentos desproporcionais, levando a um processo de morrer prolongado e com sofrimento físico ou psicológico, isto é, de um aprofundamento das características que tornam, de fato, a morte uma espécie de hipermorte.

Outro vocábulo que vem sendo utilizado por alguns autores é a ortotanásia, que pode ser demarcada como a morte no seu tempo certo, sem os tratamentos desproporcionais (distanásia) e sem abreviação do processo de morrer (eutanásia). (SIQUEIRA-BATISTA; SCHRAMM, 2005, p. 114). 


\section{Educere "Educare \\ RevISTA de EduCACÃo}

Programa de Pós-Graduação em Educação - Universidade Estadual do Oeste do Paraná

\section{Uma leitura de Mar Adentro}

Tranquilo, você está cada vez mais tranquilo! Agora, imagine uma tela, uma tela de cinema que se abre perante você e o leva para uma viagem incrivel de reflexões sobre a vida, a morte, a eutanásia, o suicídio assistido, o direito de viver e de morrer com dignidade, a ética, a bioética, o direito e o biodireito.

Concentre-se em sua respiração, fazendo uma analogia com as ondas do mar que vem e vão, que adentram sua alma, ajudando todo o seu corpo a relaxar, a se sentir em paz!

É por meio da leitura de um livro de meditação, feita por Gené (personagem representada pela atriz Clara Segura), diretora da Associação Direito a Morrer Dignamente (ADMD) - uma das mais ativas ONGs mundiais pela legalização da eutanásia, a Ramón Sampedro (Javier Bardem), que se inicia o filme Mar Adentro. A sensação de paz, então, é interrompida abruptamente com um estrondo de trovão, que retira Ramón de sua contemplação absorta do litoral da Galícia, noroeste da Espanha, que um dia lhe abriu as portas para o mundo e noutro determinou sua única janela para o universo: a do seu quarto.

O filme relata a história verídica de Ramón Sampedro Cameán, nascido em 5 de janeiro de 1943, no Município de Puerto del Son, na Espanha. Com 18 anos de idade, ele ingressa na Marinha, com a intenção de viajar e conhecer o mundo.

Como mecânico, trabalhava em navios de uma companhia que se dedicava ao transporte de petróleo. Aos 25 anos, sofre um acidente ao mergulhar no mar em ressaca, do alto de um rochedo, chocando sua cabeça contra a areia resultando na fratura da sétima vértebra cervical, o que o deixou tetraplégico e condenado a viver para sempre em uma cama, enquanto "Deus quiser".

Diante de tal situação, podemos dizer que a autonomia do sujeito em relação à sua própria vida fica limitada na medida em que diversas religiões postulam pela sacralidade da vida, considerando-a como um bem supremo, inviolável, até mesmo quando a sobrevivência passa a ser um fardo, quando a 


\section{Educere "Educare \\ RevISTA DE Educacão}

Programa de Pós-Graduação em Educação - Universidade Estadual do Oeste do Paraná

dignidade deixa de estar presente, quando a felicidade não pode mais ser alcançada. Afinal, "não há sofrimento na Terra que o Céu não possa curar".

Por isso, antes de adentrarmos nas questões da vida e da morte, precisamos nos libertar dos aprisionamentos causados pelos preconceitos, pelos discursos reproduzidos pelo senso comum, pelo imaginário que se originou ao redor da vida e da morte. Assim, dado que a "vida é bela", conforme orientação do Manual de Bioética denominado Chaves para a Bioética, editado pela Comissão Nacional da Pastoral Familiar e distribuído durante a "Jornada Mundial da Juventude", no Rio de Janeiro, em 2013, é urgente reencontrar em nós e nos outros "um olhar de encantamento, é necessário tirar os obstáculos que nos cegam diante das grandes questões bioéticas com as quais somos todos confrontados", e as quais "nos deixam frequentemente desamparados" (p. 12).

A condição vivenciada após o acidente leva Ramón a definir-se como "uma cabeça viva num corpo morto", tornando a morte seu maior anseio, uma vez que o libertaria do inferno do qual não podia escapar sem ajuda de alguém. Para ele: a vida só é vida racional enquanto for prazeroso e voluntário o fato de vivê-la. Não há ato mais cruel que o de proibir a uma pessoa o direito de se libertar de seus sofrimentos, ainda que isso implique ajudá-la a morrer. (SAMPEDRO, 2005, p. 117).

Sem poder mover o corpo do pescoço para baixo, solicitou à Justiça espanhola permissão para a prática do suicídio assistido, argumentando que, para ele, "viver era um direito, não uma obrigação". Ramón foi o primeiro cidadão espanhol a requerer tal prática, argumentando que era direito de cada pessoa dispor de sua própria vida e que, no seu caso, estava impossibilitado de fazê-lo sem auxílio de outrem. Entretanto, seu pedido foi indeferido. Mesmo assim, em janeiro de 1998, mediante a ingestão de cianeto de potássio, supostamente auxiliado por uma amiga, pôs um ponto final em sua existência corpórea. Toda a ação foi gravada em vídeo. O fato foi contado pelo próprio Ramón Sampedro no livro Cartas do Inferno, o qual posteriormente foi objeto do filme Mar Adentro. 


\title{
Educere "Educare \\ ReVISTA DE EdUCACÃ̃o
}

Programa de Pós-Graduação em Educação - Universidade Estadual do Oeste do Paraná

\section{Reflexões bioéticas em torno do filme Mar Adentro}

O filme traz à tona a polêmica em torno da morte assistida, tema caro à bioética.

\begin{abstract}
Além de comover plateias do mundo inteiro, o filme trouxe a público uma série de questionamentos éticos sobre a vida e a morte, dentre as quais se destacam: qual o valor da vida humana quando marcada por deficiências que tolhem a liberdade e a autonomia? O que fazer quando não se encontra mais motivos para viver? Continuar a viver tentando ressignificar a vida seria possível ou a opção pelo suicídio assistido seria desejável como o fez Ramón Sampedro? (PESSINI, 2008, P. 55).
\end{abstract}

Ramón Sampedro permaneceu tetraplégico por quase 29 anos, lutando convicta e continuamente pelo direito de morrer dignamente. A racionalidade e sensibilidade estética impediam-no de resignar-se a sobreviver naquela condição degradante.

Conforme estudo feito por Dantas (2008), pelo menos três tipos de personagens se posicionavam, durante a ação do filme, contra, a favor ou se abstinham de opinar sobre a obstinada intenção do protagonista: a dedicada cunhada, Manuela (Mabel Ribera); o intransigente irmão mais velho, José (Celso Bugallo); o resignado pai, Joaquín (Joan Dalmau); e o inocente sobrinho, Javier (Tamar Novas).

A devota Manuela defendia os direitos de Ramón, mas se abstinha de expressar seus sentimentos, argumentando que sua preferência, na verdade, não tinha importância, já que o desejo de Ramón pela morte era muito claro.

$\mathrm{Na}$ mesma esteira se encontravam o sobrinho e o pai, este praticamente silencioso durante quase todo o filme, mas em uma frase resume toda a sua angústia, tristeza e frustração: "Só há uma coisa pior do que a morte de um filho: que ele queira morrer!". 


\section{Educere "Educare \\ RevISTA de EduCACÃo}

Programa de Pós-Graduação em Educação - Universidade Estadual do Oeste do Paraná

Por outro lado, o irmão José ia severamente de encontro às ideias de Ramón, sem sequer ouvir o ponto de vista dele. Essa postura intransigente e autoritária talvez seja o maior óbice para a implantação da bioética, visto que a alteridade é um de seus pilares, exercício contínuo de colocar-se no lugar do outro, de dialogar com o próximo, de enxergar o mundo por um ângulo que não o nosso.

E a educação é um caminho para isso, na medida em que ela propõe o convivio e o relacionamento de pessoas com habilidades e competências diferentes, condições absolutamente necessárias para o desenvolvimento de valores éticos, tais como a dignidade do ser humano, o respeito ao outro, a igualdade, a equidade e a solidariedade (BRASIL/MEC, 1998).

Padre Francisco (José María Pou), outro personagem do filme, pároco da cidade e também tetraplégico, pronuncia-se na televisão sobre o caso e acusa a família da falta de cuidado com que Ramón era tratado, sem ao menos conhecer de perto a realidade, manifestando seu desejo de falar e convencê-lo de que existem inúmeras razões para continuar vivendo, o que evidencia uma vez mais que posturas inflexíveis e austeras não captam a dimensão multifacetada do processo de morrer.

O diagnóstico de especialistas confirmando a impossibilidade científica de lhe devolver o equilíbrio entre cérebro e corpo, levou Ramón a pensar na morte como único caminho para libertá-lo daquela dor absurda.

Com o passar dos anos e já cansado da vida que levava, Sampedro (2005) descobriu o modo de realizar seu desejo de morrer de forma racional e humana: o suicídio assistido. Para ele, seu desejo não significava, necessariamente, estar desesperado, triste ou necessitado de carinho. Tratava-se apenas de procurar a sensatez na razão humana, a qual deveria sempre prevalecer.

Em abril de 1993, ele então recorreu aos Tribunais com uma demanda formalmente apresentada por seu advogado que, em síntese, perguntava se a 


\section{Educere "Educare \\ RevISTA DE Educacão}

Programa de Pós-Graduação em Educação - Universidade Estadual do Oeste do Paraná

pessoa que lhe prestasse ajuda deveria ser sancionada judicialmente por prestar ajuda a alguém que conscientemente desejava morrer.

Para isso procurou a Associação Direito a Morrer Dignamente (ADMD). Gené, diretora da instituição, esclarece que o trabalho oferecido pela organização se limitava a apoio psicológico, assessoria jurídica, sem participação ativa na prática da morte digna.

Segundo a ADMD, existem quatro pontos que devem ser observados em relação ao pedido da eutanásia:

O primeiro é que o doente tenha manifestado reiteradamente o desejo de interromper a vida. O segundo é que a doença seja crônica ou grave. $\mathrm{O}$ terceiro, que a eutanásia seja feita por um médico. $\mathrm{E}$ o quarto, que a doença provoque sofrimento físico ou psíquico. Foi o caso de Ramón Sampedro que nos fez incluir este último ponto. Ramón não era um doente terminal, mas tampouco queria viver preso numa cama. Ele nos deixou a reflexão de que a vida não é apenas respirar. (BAU, 2005, on-line).

Gené, então, apresentou Ramón à advogada Júlia (Belén Ruenda), que sofre de uma doença degenerativa chamada Cadasil, na esperança de que ela o ajudasse na batalha judicial em busca da autorização para o tão esperado suicídio assistido.

Ramón lutou por quase três décadas pelo direito de morrer dignamente, requerendo à Justiça espanhola o direito da prática do suicídio assistido, sem que nenhuma pessoa fosse responsabilizada criminalmente. Em todas as instâncias seu pedido foi indeferido. O mesmo acontecendo no Tribunal Europeu dos Direitos do Homem e no Comitê de Direitos Humanos da ONU. Ante as impossibilidades legais, Ramón entendeu que a única saída do inferno - como definia sua vida - seria o suicídio auxiliado por alguma pessoa generosa (MATZEMBACHER; FERRAREZE FILHO, 2009). 


\section{Educere "Educare \\ Revista de Educacẽo}

Programa de Pós-Graduação em Educação - Universidade Estadual do Oeste do Paraná

Muitas vezes, durante o filme, Ramón é acusado de pensar somente em si próprio, de agir conforme seus interesses pessoais. Entretanto, entendemos que isso não procede, pois se assim fosse, ele não estaria preocupado em preservar a incolumidade daquele que o ajudasse em seu suicídio, ato digno de preocupar-se com o outro, mesmo para além de sua morte.

Em frente do Tribunal, à espera da chegada de Ramón, um grupo de pessoas solidárias com seu pedido gritava: "Dignidade, dignidade! Viver é um direito e não uma obrigação!" Chegando ao Tribunal, Ramón é interpelado por repórteres acerca de ele ter sido o único espanhol a pedir a eutanásia voluntária. Entretanto, Ramón respondeu que ele era o único a solicitá-la publicamente, mas que isso era feito de modo clandestino há anos.

Isso nos parece muito grave, pois não é de hoje que ouvirmos notícias sobre a prática indiscriminada da eutanásia em unidades de terapia intensiva brasileiras (COLLUCCI; GOIS, 2005).

Portanto, dada a falta de regulamentação em nosso ordenamento jurídico, uma discussão ampla a respeito do tema, com a participação de diversos setores da sociedade, ouvindo-se especialistas de várias áreas do saber, faz-se urgente e necessária.

Sendo assim, fica fácil de percebermos que a construção de valores laicos perpassa pela educação, necessariamente. E o cinema é uma ótima opção para o despertar de uma nova consciência ética, mais secular e menos dogmática, um patamar mínimo para refletirmos, livre de prejulgamentos e temores, sobre o real sentido da morte e, por consequência, de nossas próprias vidas.

Pois, sem a compreensão do sentido da morte, tampouco entenderemos o sentido da vida, muito menos o pedido de alguém por uma morte racional ou pelo direito de dar fim à sua própria existência como uma renúncia a um bem pessoal. Para isso, a vida precisa ser concebida sem crendices ou superstições, para nos libertarmos do temor da morte e da dor (SAMPEDRO, 2005). 


\section{Educere "Educare \\ RevISTA DE EducAcão}

Programa de Pós-Graduação em Educação - Universidade Estadual do Oeste do Paraná

\section{CONSIDERAÇÕES FINAIS}

A saga de Ramón Sampedro e toda a sua repercussão foram, portanto, fundamentais para o desenvolvimento do filme, que mostra sua luta, a exposição pública do seu drama e o debate nos Tribunais. O apelo dramático do enredo provoca emoção do público que assiste ao filme. As cenas e os diálogos exibidos por meio de imagens produzem sentimentos a partir das emoções vivenciadas, podendo-se dizer que a arte fala para os nossos sentidos, nossa subjetividade; daí a importância do cinema para o processo educacional.

Os filmes cinematográficos são produções em que a imagem em movimento, aliada às múltiplas técnicas de filmagem e montagem e ao próprio processo de produção e ao elenco selecionado, cria um sistema de significações.

São histórias que nos interpelam de um modo avassalador porque não dispensam o prazer, o sonho e a imaginação. Elas mexem com nosso inconsciente, embaralham as fronteiras do que entendemos por realidade e ficção. Quando dizemos que o cinema cria um mundo ficcional, precisamos entendê-lo como uma forma de a realidade apresentar-se. (FABRIS, 2008, p. 118).

Embora a finalidade do cinema não seja especificamente a pedagógica, pode-se dizer que ele apresenta também um viés educativo, na medida em que aborda vários aspectos da vida humana, o que favorece a discussão e a exploração de diversos temas complexos.

Sendo assim, as abordagens dilemáticas em torno da vida, da morte, da eutanásia, do suicídio assistido, do direito de morrer com dignidade fazem de Mar Adentro o cenário perfeito para a discussão das questões bioéticas ligadas à terminalidade da vida, bem como de seus reflexos no campo jurídico. 


\section{Educere Educare \\ REVISTA DE EDUCACÃ̃}

Programa de Pós-Graduação em Educação - Universidade Estadual do Oeste do Paraná

\section{REFERÊNCIAS}

BARROSO, L.R.; MARTEL, L.C.V. A morte como ela é: diginidade e autonomia individual no final da vida. In: GOZZO, D.; LIGIERA, W.R. (Orgs.). Bioética e direitos fundamentais. São Paulo: Saraiva, 2012.

BAU, A. Pela hora da morte. Revista Super Interessante. 2005. Entrevista concedida a Érica Montenegro. Disponivel em: <http://super.abril.com.br/saude/pela-hora-morte-445566.shtml>. Acesso em: 06 abr. 2018.

BRASIL. Referencial curricular nacional para a educação infantil. Ministério da Educação e do Desporto. Brasília: MEC, v. 1, 1998.

CEDH - Corte Europeia de Direitos Humanos. Research report: Bioethics and the case-law of the Court. Council of Europe/European Court of Human Rights, 2016.

COLUCCI, C.; GOIS, A. Médicos revelam que eutanásia é prática habitual em UTIs do país. Folha de São Paulo. 2005. Disponível em: <http:/ / www1.folha.uol.com.br/folha/cotidiano/ult95u105876.shtml>. Acesso em: 20 abr. 2018.

DANTAS, A.A. O cinema como instrumento didático para a abordagem de problemas bioéticos: uma reflexão sobre a eutanásia. Dissertação (Mestrado em Ciências da Saúde), Faculdade de Medicina, Universidade Federal de Uberlândia, 2008.

DINIZ, M. H. O estado atual do biodireito. 8. ed. São Paulo: Saraiva, 2011.

DWORKIN, R. Dominio da vida: aborto, eutanásia e liberdades individuais. Tradução Jefferson Luiz Camargo. São Paulo: Martins Fontes, 2003.

ESTADÃO. Cientista de 104 anos se prepara para suicidio assistido na Suiça. 2018. Disponivel em: <http://saude.estadao.com.br/noticias/geral,cientista-de104-anos-se-prepara-para suicidio-assistido-na suica,70002301950>. Acesso em: 12 maio 2018.

FABRIS, E.H. Cinema e educação: um caminho metodológico. Educação \& Realidade, v. 33, n. 1, p. 117-133, 2008. 


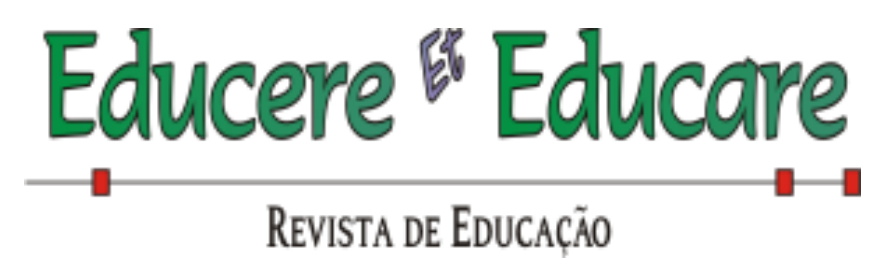

Programa de Pós-Graduação em Educação - Universidade Estadual do Oeste do Paraná

FOUCAULT, M. Em defesa da sociedade. Tradução Maria Ermantina Galvão. São Paulo: Martins Fontes, 2005.

KOVÁCS, M.J. Bioética nas questões da vida e da morte. Psicologia USP, v. 14, n. 2, p. 115-167, 2003.

MAR ADENTRO. Direção: Alejandro Amenábar. Espanha:[s.n.]; 2004. 1 filme (125 min), son, color.

MATZEMBACHER, A.; FERRAREZE FILHO, P. Aspectos éticos e jurídico-penais sobre a eutanásia. Direito em debate, ano XVII, n. 31, p. 11-33, 2009.

MORAES, I.I.G.; OLIVEIRA, I.G. Educar para o viver e o morrer. Educere et Educare - Revista de Educação, v. 5, n. 10, 2010. Disponivel em: <http://erevista.unioeste.br/index.php/educereeteducare/article/view/2661/4062>. Acesso em 21 maio 2018.

PESSINI, L. Morte, solução de vida? Uma leitura bioética do filme Mar Adentro. Revista Bioética, v. 16, n. 1, p. 51-60, 2008.

SAMPEDRO, R. Cartas do inferno. Tradução Lea Zylberlicht. São Paulo: Editora Planeta do Brasil, 2005.

SIQUEIRA-BATISTA, R.; SCHRAMM, F.R. Conversações sobre a boa morte: o debate bioético acerca da eutanásia. Cadernos de Saúde Pública, v. 21, n. 1, p. 111-119, 2005.

TJSP. $6^{a}$ Câmara Criminal. Recurso em Sentido Estrito $\mathbf{n}^{\circ}$ 993.07.004015-7. Relator: Des. Luís Gustavo da Silva Pires. Julgamento: 14 dez. 2009.

Recebido em: 28/05/2018

Aprovado em: 18/11/2018 